\title{
EDITORIAL
}

\section{Evidence supports the superiority of closed ICUs for patients and families: Yes}

\author{
Jean-Louis Vincent ${ }^{*}$
}

(C) 2016 Springer-Verlag Berlin Heidelberg and ESICM

\section{"Too many cooks..."}

Most intensive care units (ICUs) around the world, with the general exception of the USA, now operate according to a "closed" model, i.e., patients are admitted under the full responsibility of a trained intensivist, as opposed to the "open" format in which patients are admitted under the care of another attending physician and intensivists are just available for consultation [1]. In a worldwide study of 1265 ICUs in 75 countries in 2007, $83 \%$ of the units were closed: North America had the lowest proportion of closed ICUs (63\%) and Western Europe the highest (89\%) [1]. Of 111 ICUs across nine Canadian provinces, 94 (85\%) reported a closed format model of care in 2015 [2]. In Asia, Arabi et al. [3] reported that 216 of 335 (65\%) ICUs surveyed in 2013 were closed format and in the UK, all ICUs analyzed as part of the ICNARC project in 2010/2011 reported that their unit model was closed [4]. Similar to the situation in the UK, in Australia and New Zealand the vast majority of ICUs are run in closed format [5].

There is good evidence that closed ICUs are associated with better outcomes and better quality of care, both in general [6-10] and in subspecialty [11] units. Several studies have reported a positive impact on outcomes when the ICU model was changed from open to closed [6-8]. In one example, a before-after cohort study, Parikh et al. [7] reported that the change from an open to a closed format was associated with shorter ICU stay and improved quality measures, including less ventilator-associated pneumonia and central vein access device infection. ICU costs were also reduced [7]. Kahn et al.

\footnotetext{
*Correspondence: jlvincent@intensive.org

Department of Intensive Care, Erasme Hospital, Université Libre de Bruxelles, Route de Lennik 808, 1070 Brussels, Belgium
}

For contrasting viewpoints, please go to doi:10.1007/s00134-016-4438-9 and doi:10.1007/s00134-016-4510-5. also reported improved quality of care in closed (highintensity) compared to open (low-intensity) ICUs, as shown by increased use of evidence-based quality indicators including sedation interruption and intensive insulin treatment [9]. In an early meta-analysis of 26 such studies comparing closed and open ICU models, Pronovost et al. [10] reported that a closed model (or high-intensity intensivist staffing) was associated with lower mortality and shorter length of stay than an open format (lowintensity intensivist staffing). More recently, Wilcox et al. similarly reported that high-intensity intensivist staffing was associated with reduced ICU and hospital mortality and shorter stay in a meta-analysis of 52 studies [12].

Clearly, therefore, closed-format ICUs have a beneficial impact on patient outcomes. However, they also have positive effects on other aspects, including staff and family satisfaction. These concepts are difficult to define and quantify, and the published data on this issue are relatively sparse. Nevertheless, good communication with adequate provision of coherent information is known to be a key factor in family satisfaction with intensive care [13]. Having a single physician in charge of patient management (closed format) will ensure that communication about treatments and prognoses is consistent; having several specialists involved in patient management can result in mixed and confusing messages. In an early study by Carson et al. [6], nurses working in closed ICUs were more likely to feel confident in the clinical judgment of the attending physician than those in open ICUs. Paul Olson et al. reported that surgeons working in a unit where an ICU physician was primarily responsible for all patients were significantly less likely to report conflicts with their intensivist colleagues than surgeons working on a unit where the operative surgeon was primarily responsible for his/her patients [14]. Such conflicts are likely to impact negatively on communication with patients and families. Evaluation of prognosis may

\section{Springer}


also vary among physicians, and relatives may choose to believe the most optimistic report, creating tension if the patient's condition then deteriorates. In a recent study comparing relatives' satisfaction with the "courtesy, respect, compassion" shown by members of staff, the percentage of families that reported complete satisfaction was higher in a closed medical ICU than in an open neuro-ICU [15]. The authors suggested that this may have been related to the difference in format, although clearly their data were unable to demonstrate causality.

There is good evidence that intensivist-led patient management is associated with better patient outcomes than are achieved in units without intensivist cover. Moreover, an ICU team led by an experienced intensivist in a closed-format unit provides quality care more efficiently than in an open unit where no one, including the patient and relatives, is quite sure who has final responsibility for patient management. This model ensures that patients and their families receive optimal appropriate, coordinated management and consistent good communication, a key marker of satisfaction; and surely our patients deserve the very best.

\section{Compliance with ethical standards}

\section{Conflicts of interest}

I have no conflicts of interest to declare related to this manuscript.

Received: 11 July 2016 Accepted: 27 July 2016

Published online: 1 September 2016

\section{References}

1. Sakr Y, Moreira CL, Rhodes A, Ferguson ND, Kleinpell R, Pickkers $P$, Kuiper MA, Lipman J, Vincent JL (2015) The impact of hospital and ICU organizational factors on outcome in critically ill patients: results from the extended prevalence of infection in intensive care study. Crit Care Med 43:519-526

2. Holodinsky JK, Hebert MA, Zygun DA, Rigal R, Berthelot S, Cook DJ, Stelfox HT (2015) A survey of rounding practices in Canadian adult intensive care units. PLoS One 10:e0145408
3. Arabi YM, Phua J, Koh Y, Du B, Faruq MO, Nishimura M, Fang WF, Gomersall C, Al Rahma HN, Tamim H, Al-Dorzi HM, Al-Hameed FM, Adhikari NK, Sadat M (2016) Structure, organization, and delivery of critical care in Asian ICUs. Crit Care Med (in press)

4. Wilcox ME, Harrison DA, Short A, Jonas M, Rowan KM (2014) Comparing mortality among adult, general intensive care units in England with varying intensivist cover patterns: a retrospective cohort study. Crit Care 18:491

5. Deane AM (2014) Intensivists under threat: who's in charge here? Crit Care Resusc 16:138-139

6. Carson SS, Stocking C, Podsadecki T, Christenson J, PohIman A, MacRae S, Jordan J, Humphrey H, Siegler M, Hall J (1996) Effects of organizational change in the medical intensive care unit of a teaching hospital: a comparison of 'open' and 'closed' formats. JAMA 276:322-328

7. Parikh A, Huang SA, Murthy P, Dombrovskiy V, Nolledo M, Lefton R, Scardella AT (2012) Quality improvement and cost savings after implementation of the Leapfrog intensive care unit physician staffing standard at a community teaching hospital. Crit Care Med 40:2754-2759

8. Treggiari MM, Martin DP, Yanez ND, Caldwell E, Hudson LD, Rubenfeld GD (2007) Effect of intensive care unit organizational model and structure on outcomes in patients with acute lung injury. Am J Respir Crit Care Med 176:685-690

9. Kahn JM, Brake H, Steinberg KP (2007) Intensivist physician staffing and the process of care in academic medical centres. Qual Saf Health Care 16:329-333

10. Pronovost PJ, Angus DC, Dorman T, Robinson KA, Dremsizov TT, Young TL (2002) Physician staffing patterns and clinical outcomes in critically ill patients: a systematic review. JAMA 288:2151-2162

11. Rodricks MB, Hawkins SE, Anderson GA, Basignani C, Tuppeny M (2015) Mandatory intensivist management decreases length of stay, facilitates an increase in admissions and minimizes closure of a neurocritical care unit. Neurocrit Care 23:307-312

12. Wilcox ME, Chong CA, Niven DJ, Rubenfeld GD, Rowan KM, Wunsch H, Fan E (2013) Do intensivist staffing patterns influence hospital mortality following ICU admission? A systematic review and meta-analyses. Crit Care Med 41:2253-2274

13. Hunziker S, McHugh W, Sarnoff-Lee B, Cannistraro S, Ngo L, Marcantonio E, Howell MD (2012) Predictors and correlates of dissatisfaction with intensive care. Crit Care Med 40:1554-1561

14. Paul Olson TJ, Brasel KJ, Redmann AJ, Alexander GC, Schwarze ML (2013) Surgeon-reported conflict with intensivists about postoperative goals of care. JAMA Surg 148:29-35

15. Hwang DY, Yagoda D, Perrey HM, Tehan TM, Guanci M, Ananian L, Currier PF, Cobb JP, Rosand J (2014) Assessment of satisfaction with care among family members of survivors in a neuroscience intensive care unit. J Neurosci Nurs 46:106-116 